\title{
The Empirical Study on R\&D Efficiency of High-Tech Industry in China
}

\author{
Hailing Zhao
}

\begin{abstract}
This study applies non-radial data envelopment analysis (DEA) to analyze the research and development (R\&D) efficiency of 28 provinces of China during the period of 2007-2011. In addition, these 28 provinces are divided into three big regions, that is, eastern, middle and western regions. The results show that Beijing and Guangdong have relatively best $R \& D$ efficiencies and most of provinces in middle and western regions have lower efficiencies relative to those provinces in eastern region. Moreover, the gap of $R \& D$ efficiency between eastern region and middle and western regions converged at one point in 2010, but then widened again soon afterward.
\end{abstract}

Index Terms-R\&D efficiency, slacks-based measure, high-tech industry.

\section{INTRODUCTION}

With the development of Chinese economy, the economic backbone of China is transforming from traditional industries to high-tech industries. The main aim of the transformation is to develop and research new technologies and apply these new technologies to production in order to raise the quality of products, increase the amount of exports, and control environment pollution. 105 high-tech industry parks have built in main provinces between 1991 and 2012. Moreover, investment in high-tech industry in China keeps increasing year by year. Hence, measuring R\&D efficiency can help the Chinese high-tech industry develop further.

There are two main approaches to measure efficiency, including data envelopment analysis (DEA) and stochastic frontier analysis (SFA). SFA is an econometric approach while DEA is a mathematical programming approach to measure the relative efficiency of decision making units (DMUs) with multiple inputs and outputs. DEA consists of two different types, that is, radial and non-radial. The radial DEA model was firstly proposed in 1978 by Charnes, Cooper and Rhodes (CCR) [1] and it was later extended in 1984 by Banker, Charnes and Cooper (BCC) [2]. On the other hand, there are non-radial models which take into account the slacks of each input or output, and input and output variables are allowed to decrease or increase at different rates. The non-radial model, named slacks-based measure (SBM), was proposed by Tone in 2001 [3]. Therefore, this article applies SBM model to analyze the performance of the Chinese high-tech industry.

The remainder of this study is organized as follows: Section II shows a review of the efficiency of the Chinese

Manuscript received June 24, 2014; revised October 16, 2014.

Hailing Zhao is with Pusan National University, 2, Busandaehak-ro 63beon-gil, Geumjeong-gu, Busan 609-735, South Korea (e-mail: luckysophia00@gmail.com). high-tech industry. Section III introduces the methodology of SBM. Section IV shows data employed, and Section V shows the results. Section VI presents the conclusion.

\section{LITERATURE REVIEW}

There are many studies employing radial DEA to measure efficiency of Chinese high-tech industry. Shan (2011) [4] applied DEA-Malmquist to measure technical change, technology change and total factor productivity (TFP) and analyzed R\&D efficiency of Chinese high-tech industry, and found that average of technical efficiency of high-tech industry was 0.864. Li, Ren, Tao and Jiang (2012) [5] analyzed the R\&D efficiencies of 28 provinces of China in 2010 using three-stage DEA and results found that R\&D efficiency of each province significantly changed and the mean of R\&D efficiencies apparently declined. Xie, $\mathrm{Hu}$ and Xia (2007) [6] employed DEA to measure R\&D efficiency, technical efficiency and scale efficiency of each province of China and used econometric approach to examine if R\&D inputs and market competition had an impact on efficiency. Moreover, the empirical results show that the whole level of $\mathrm{R} \& \mathrm{D}$ efficiency is low and the gap between each province is great. Chen and Liang (2010) [7] used stochastic frontier analysis to analyze intermediate R\&D efficiency and final R\&D efficiency from 2000 to 2007. Furthermore, results found that final R\&D efficiency was higher than intermediate R\&D efficiency before the year 2003 and vice verse after the year 2003. Wang (2012) [8] applied DEA to measure technical efficiency, pure technical efficiency, and scale efficiency of high-tech industry of Anhui province, which is one of Chinese provinces, during the period of 2002-2011. The finding found that high-tech industry in Anhui province increased quickly during periods of the tenth five and the eleventh five, and input scale is the main reason leading to R\&D inefficiency. Zhao (2012) [9] measures change of technical efficiency, pure technical efficiency, and scale efficiency by DEA-malmquist, and analyze R\&D development situation of high-tech industry in China, and gives some sustainable policy proposal.

So far, there are not many existing papers used non-radial DEA to analyze the R\&D efficiency of China. Xiao, Feng and Han (2012) [10] employed SBM directional distance function to measure the R\&D efficiency and economic efficiency of high-tech industry of China. Moreover, Lu (2014) [11] applied super-SBM model to analyze the R\&D efficiency of 29 provinces of China and compared the results by SBM with those by BCC. Zhao (2014) [12] employs output-oriented SBM to measure the R\&D efficiency of high-tech industry in 
China. In addition, the results illustrate that the overall R\&D efficiency of high-tech industry in China has been improved to a fair extent during the sample period but still lies at the lower level, and the R\&D efficiency of the eastern area is better than that of the western and central areas and the central area has the lowest R\&D efficiency.

\section{Methodology}

The model used in this study is non-oriented slacks-based measure (SBM) under the variable returns to scale, which directly deals with input excess and output shortfall slacks. SBM was introduced by Tone (2001) and has two important properties, that is, units invariant and monotone.

There are $\mathrm{n}$ DMUs with the input and output matrices $X=\left(x_{i j}\right) \in R^{m^{*} n}$ and $Y=\left(y_{i j}\right) \in R^{s^{* n}}$, respectively. Moreover, $X>0$ and $Y>0$ should be assumed. The production possible set $P$ is defined as

$$
P=\left\langle(x, y) \mid x \geq X \lambda, y \leq Y \lambda, \sum \lambda=1\right\rangle
$$

where $\lambda$ is a nonnegative vector in $R^{n}$.

The SBM expression is following as:

$$
\min \rho=\frac{1-\frac{1}{m} \sum_{i=1}^{m} \frac{s_{i}^{-}}{x_{i o}}}{1+\frac{1}{s} \sum_{r=1}^{s} \frac{s_{r}^{+}}{y_{r o}}}
$$

Subject to

$$
x_{0}=X \lambda+s^{-}
$$

$$
\begin{gathered}
y_{0}=Y \lambda-s^{+} \\
\lambda \geq 0, s^{-} \geq 0, s^{+} \geq 0
\end{gathered}
$$

In this expression, $s^{+}$and $s^{-}$means input excess or output shortfall, respectively, and called as slacks.

\section{DATA}

There are 31 provinces and two special administrative regions in China. However, there is missing data in Tibet, Xinjiang and Qinghai. Hence, the sample data in this study only includes 28 provinces. In addition, two special administrative regions, namely Hong Kong and Macau, are not included as well.

As can be seen in table I, this article consists of three inputs and two outputs. Inputs include full-time equivalent of R\&D personnel $\left(\mathrm{I}_{1}\right)$, intramural expenditure on $\mathrm{R} \& \mathrm{D}\left(\mathrm{I}_{2}\right)$, and product development costs $\left(\mathrm{I}_{3}\right)$. Patent application $\left(\mathrm{O}_{1}\right)$ and the amount of new products $\left(\mathrm{O}_{2}\right)$ are treated as outputs. Moreover, all of data is from the China statistics yearbook on high-tech industry.

Table I illustrates the overall mean of each input continually increased from 2007 to 2011, and the average of number of the patent application slightly decreased from 2007-2008, but has grown dramatically since 2008. There is an upward trend in the average of the amount of new products during the period of 2007-2008, and then a significantly boom after 2009. With the economic development of China,

\begin{tabular}{|c|c|c|c|c|c|c|}
\hline & & $\mathrm{I}_{1}$ & $\mathrm{I}_{2}$ & $\mathrm{I}_{3}$ & $\mathrm{O}_{1}$ & $\mathrm{O}_{2}$ \\
\hline & Max & 92877.08 & 1801061.5 & 2005421.3 & 20996 & 21277341 \\
\hline \multirow[t]{4}{*}{2007} & Min & 11.8 & 310.5 & 1537.5 & 4 & 514.2 \\
\hline & Mean & 8865.01 & 194733.38 & 232731.8 & 1229.89 & 3809047.1 \\
\hline & STD & 17463.86 & 362875.06 & 422828.64 & 3921.42 & 5840689.4 \\
\hline & Max & 114772 & 2275140 & 2683224 & 12579 & 32010850 \\
\hline \multirow[t]{4}{*}{2008} & Min & 167 & 2282 & 2914 & 1 & 3000 \\
\hline & Mean & 10180.68 & 233990.71 & 285091.36 & 854.04 & 4648763 \\
\hline & STD & 21569.93 & 454849.4 & 557976.27 & 2378.43 & 7874935.4 \\
\hline & Max & 116894 & 2789522 & 3188554 & 17525 & 34738828 \\
\hline \multirow[t]{4}{*}{2009} & Min & 155 & 2447 & 2873 & 6 & 15580 \\
\hline & Mean & 11415.79 & 276282.39 & 330140.04 & 1135.46 & 4462336.5 \\
\hline & STD & 22790.67 & 546259.71 & 633112.13 & 3273.27 & 7737583.4 \\
\hline & Max & 156235 & 3630850 & 2710412 & 31356 & 61567664 \\
\hline \multirow[t]{4}{*}{2010} & Min & 227 & 3672 & 3962 & 8 & 17900 \\
\hline & Mean & 14247.43 & 345472.5 & 359310.14 & 1791.32 & 5892639.5 \\
\hline & STD & 30481.82 & 705153.13 & 596961.03 & 5861.64 & 12352000 \\
\hline & Max & 167068.88 & 4551770.4 & 5503043.4 & 36742 & 72184339 \\
\hline \multirow[t]{3}{*}{2011} & Min & 159.3 & 4563.7 & 4610.2 & 14 & 37970.4 \\
\hline & Mean & 15222.34 & 441482.03 & 545066.28 & 2775.25 & 6877644.9 \\
\hline & STD & 32404.89 & 887405.89 & 1106841.3 & 6989.06 & 14624876 \\
\hline
\end{tabular}
high-tech industry became the main area that the Chinese government would invest in. Therefore, all of inputs continued to increase through the whole period of 2007-2011.

TABLE I: BASIC STATISTICS 
TABLE II: THE R\&D EFFICIENCY

\begin{tabular}{|c|c|c|c|c|c|c|c|}
\hline & & 2007 & 2008 & 2009 & 2010 & 2011 & Mean \\
\hline \multirow{11}{*}{ Eastern } & Beijing & 1.0000 & 1.0000 & 1.0000 & 1.0000 & 1.0000 & 1.0000 \\
\hline & Tianjin & 1.0000 & 0.5619 & 1.0000 & 1.0000 & 1.0000 & 0.9124 \\
\hline & Shanghai & 0.7213 & 1.0000 & 0.6489 & 0.5074 & 0.5828 & 0.6921 \\
\hline & Guangdong & 1.0000 & 1.0000 & 1.0000 & 1.0000 & 1.0000 & 1.0000 \\
\hline & Hebei & 0.1741 & 0.2647 & 0.3986 & 0.2784 & 0.1810 & 0.2594 \\
\hline & Liaoning & 0.2782 & 0.1725 & 0.2351 & 0.2929 & 0.2793 & 0.2516 \\
\hline & Jiangsu & 0.3349 & 1.0000 & 1.0000 & 0.3956 & 1.0000 & 0.7461 \\
\hline & Zhejiang & 0.3620 & 0.2246 & 0.3962 & 0.4548 & 0.5774 & 0.4030 \\
\hline & Fujian & 0.3332 & 1.0000 & 0.2793 & 0.3403 & 1.0000 & 0.5906 \\
\hline & Shandong & 0.4239 & 0.2149 & 0.4630 & 0.4095 & 0.6536 & 0.4330 \\
\hline & Hainan & 1.0000 & 0.9998 & 0.1591 & 0.1039 & 1.0000 & 0.6526 \\
\hline \multirow{10}{*}{ Middle } & Shanxi & 1.0000 & 1.0000 & 1.0000 & 1.0000 & 0.3268 & 0.8654 \\
\hline & Neimenggu & 0.9998 & 0.2319 & 1.0000 & 1.0000 & 1.0000 & 0.8464 \\
\hline & Jilin & 0.3445 & 0.5279 & 0.4582 & 0.4899 & 0.2600 & 0.4161 \\
\hline & Heilongjiang & 0.0839 & 0.1081 & 0.0713 & 0.0961 & 0.1112 & 0.0941 \\
\hline & Anhui & 0.1214 & 0.1841 & 0.4374 & 0.1980 & 0.5014 & 0.2885 \\
\hline & Jiangxi & 0.1301 & 0.1992 & 0.2310 & 0.2638 & 0.2148 & 0.2078 \\
\hline & Henan & 0.2349 & 0.2195 & 0.2645 & 0.3024 & 1.0000 & 0.4042 \\
\hline & Hubei & 0.2291 & 0.2217 & 0.3478 & 0.4650 & 0.2378 & 0.3003 \\
\hline & Hunan & 0.1736 & 0.2530 & 0.3276 & 0.5946 & 1.0000 & 0.4698 \\
\hline & Guangxi & 0.1138 & 0.2776 & 1.0000 & 0.7461 & 0.1830 & 0.4641 \\
\hline \multirow{7}{*}{ Western } & Chongqing & 0.2428 & 0.3289 & 0.7736 & 0.7535 & 1.0000 & 0.6198 \\
\hline & Sichuan & 0.3270 & 0.2386 & 0.2252 & 0.1770 & 0.2300 & 0.2396 \\
\hline & Guizhou & 0.2355 & 0.3897 & 0.2817 & 0.2477 & 0.5257 & 0.3361 \\
\hline & Yunnan & 1.0000 & 1.0000 & 1.0000 & 1.0000 & 0.3660 & 0.8732 \\
\hline & Shanxi & 0.2097 & 0.1751 & 0.1719 & 0.1865 & 0.1597 & 0.1806 \\
\hline & Gansu & 0.1634 & 0.1493 & 0.1858 & 0.2172 & 0.3860 & 0.2204 \\
\hline & Ningxia & 0.3447 & 0.3175 & 0.8489 & 1.0000 & 0.7038 & 0.6430 \\
\hline \multirow{4}{*}{ Mean } & Overall & 0.4493 & 0.4736 & 0.5430 & 0.5186 & 0.5886 & 0.5146 \\
\hline & Eastern & 0.6025 & 0.6762 & 0.5982 & 0.5257 & 0.7522 & 0.6310 \\
\hline & Middle & 0.3431 & 0.3223 & 0.5138 & 0.5156 & 0.4835 & 0.4357 \\
\hline & Western & 0.3604 & 0.3713 & 0.4982 & 0.5117 & 0.4816 & 0.4446 \\
\hline
\end{tabular}

\section{RESULTS}

Fig. 1 shows the overall trend of the annual mean of R\&D efficiencies. China is a very large country, and there are huge gaps in the levels of development of each province; therefore, the results are analyzed by dividing all of selected provinces into 3 big areas, that is, eastern region, middle region and western region. ${ }^{1}$

As it can be shown in Fig. 1, the overall mean of R\&D efficiency first increased to 0.5430 from 2007 to 2009 , then dropped by 0.0244 in 2010 , and finally grew to 0.5886 in

\footnotetext{
${ }^{1}$ According to the national development and reform commission of China, eastern region includes Beijing, Tianjin, Hebei, Liaoning, Shanghai, Jiangsu, Zhejiang, Fujian, Shandong, Guangdong and Hainan, and middle region consists of Heilongjiang, Jilin, Shanxi, Anhui, Jiangxi, Henan, Hubei and Hunan as well as western region comprises Sichuan, Chongqing, Guizhou, Yunnan, Tibet, Shanxi, Gansu, Qinghai, Ningxia, Xinjiang, Guangxi and Neimenggu.
}

2011. In addition, the mean of R\&D efficiency of eastern region is higher than the overall mean of R\&D efficiency for a whole period of 2007-2011. However, the mean of $R \& D$ efficiencies of middle and western regions are lower than the overall mean of that during the same period. Nevertheless, the mean of $R \& D$ efficiency in eastern region declined significantly during the period of 2008-2010, while the mean of that in middle and western regions simultaneously rose. Particularly, in 2010, the mean of R\&D efficiencies of these three regions converged at one point. However, the mean of $R \& D$ efficiency in eastern area has increased since then. Meanwhile, there is a downward trend of the means of $R \& D$ efficiencies in middle and western areas. Due to financial crisis in 2008, it was difficult to perform social financing. In addition, financial crisis had a great negative effect on exports in China so that many high-technology companies in China cut the number of staff. The financial crisis was main cause of the decline in the R\&D efficiency in eastern region. The 
industrial structure between eastern region and middle and western regions is very different. The rate of primary industry against GDP in middle and western regions is almost two times that in eastern region, while rate of tertiary industry against GDP in eastern region is much higher than that in middle and western regions. Moreover, the level of economic development in the middle and western regions greatly lags behind that in the eastern region. Hence, the financial crisis did not have a great impact on high-tech industry in middle and western regions. Furthermore, the Chinese government investment in western region increases every year. Hence, the R\&D efficiencies of middle and western regions were improved from 2008 to 2010 .

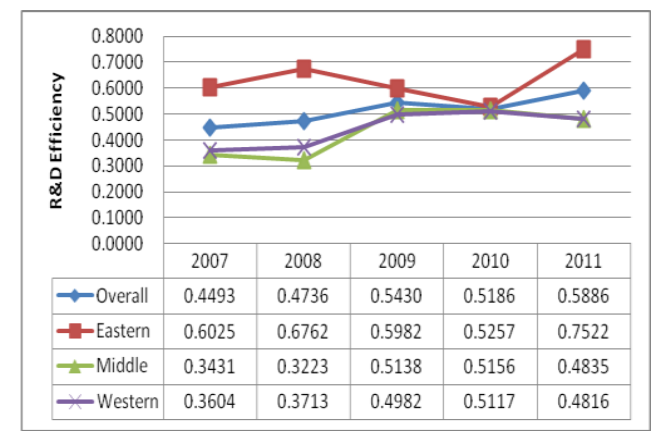

Fig. 1. Trend on the annual mean of R\&D efficiencies.

Table II illustrates the R\&D efficiency of each province. There are only two efficient provinces through the whole period of 2007-2011, which are Beijing and Guangdong. In addition, Tianjin has a higher mean of $R \& D$ efficiency with the value at 0.9124 , which is third to Beijing and Guangdong. A higher degree of openness exists in Beijing, Guangdong and Tianjin, therefore, more foreign big high-tech companies brought a great deal of money and technology to these provinces, which could help technology of these provinces to further increase. In the middle region, Shanxi (0.8654) and Neimenggu (0.8464) have the highest R\&D efficiency relative to the other provinces in the middle region, while Heilongjiang has the relatively lowest R\&D efficiency compared with all of provinces. Heilongjiang is one of main agriculture produces bases of China and mainly produces low value-added goods, which cause very low R\&D efficiency relative to other provinces. As for western region, Yunnan (0.8732) has the relatively higher value of R\&D efficiency and Shanxi (0.1806) and Sichuan (0.2396) have the relatively lower value of that. Although Chinese government increasingly invests in western region, the amount of researchers, economic situation, and other objective reasons cause the western region lag far behind the eastern region.

\section{CONCLUSIONS}

This study employs non-oriented SBM model under the variable returns to scale to analyze the $R \& D$ efficiencies of 28 provinces of China during the period of 2007-2011. Compared with radial DEA, SBM takes into account the slacks of each input or output, and input and output variables are allowed to decrease or increase at different rates. The results find that there is an overall upward trend on $R \& D$ efficiency and the R\&D efficiency of eastern region is higher than that of middle and western regions during the whole period. Moreover, the gap of R\&D efficiencies between eastern region and middle and western regions narrowed and converged at one point in 2010, and then has become wider. Due to industrial structure, amount of researchers as well as other objective reasons, Beijing and Guangdong are efficient relative to the other provinces and Tianjin is just behind them at the mean value of 0.9124 , while many of provinces in middle and western regions have relatively lower value of R\&D efficiency.

\section{REFERENCES}

[1] A. Charnes, W. W. Cooper, and E. Rhodes, "Measuring the efficiency of decision making units," European Journal of Operational Research, vol. 2, pp. 429-444, 1978.

[2] R. D. Banker, A. Charnes, and W. W. Cooper, "Some models for estimating technical and scale inefficiencies in data envelopment analysis," Management Science, vol. 30, pp. 1078-1092, 1984.

[3] K. Tone, "A slacks-based measure of efficiency in data envelopment analysis," European Journal of Operational Research, vol. 130, pp. 498-509, 2001.

[4] C. X. Shan. (2011). Analysis on R\&D efficiency of high-tech industry in China based on DEA-Malmquist. China Academic Journal Electronica Publishing House. Decision Reference. [Online]. 326(2) pp. 70-74. Available: http://wenku.baidu.com/link?url=oE-viYUxJwD4EQegxw5mma_1JO fGcveQ5JdiIvZJxgylXKflq4pUcXRZbkG5aKs YFMSOwFX-NQXU5 OTb2_2ZNHRHhg2pkCLOSbLb_LDYJBe

[5] H. W. Li, N. Ren, M. Tao, and X. J. Jiang, "Research on input-output efficiency of high-tech industry in China based on three-stage DEA model," Chinese Journal of Management Science, vol. 20, pp. 126-131, 2012.

[6] W. Xie, W. Hu, and S. M. Xia, "Study on R\&D efficiency and its determinants of Chinese high-tech industry," Science of Science and Management of S.\&T., pp. 144-149, 2007.

[7] X. D. Chen and T. Y. Liang, "An empirical research on R\&D efficiency and influence factors of China's high-tech industry based on panel data SFPT model," Studies in Science of Science, vol. 28, pp 1198-1205, 2010.

[8] Q. P. Wang, "Analysis on efficiency of the high-tech industry of Anhui province based on DEA," Journal of Suzhou University, vol. 27, pp. 19-21, 2012.

[9] L. Zhao, "The study of R\&D innovation efficiency of high-tech industries based on the method of DEA," Journal of North China Institute of Water Conservancy and Hydroelectric Power (Social Science), vol. 28, pp. 76-78, 2012.

[10] Z. L. Xiao, S. X. Feng, and S. F. Han, "Calculation on high-tech industry' two stage efficiency and analysis on its improving path in China-based on the SBM directional distance function," Industrial Economics Research, vol. 4, pp. 10-18, 2012.

[11] W. Z. Lu, "Research on technological innovation efficiency of the provinces of our country high-tech industries - based on super efficiency of S-SBM," Science Technology and Industry, vol. 14, pp 13-15, 2014

[12] H. L. Zhao, "Measurement on R\&D efficiency of high-tech industry in China," presented at the 2014 International Conference on Education and Management Science, Beijing, China, August 19-20, 2014.

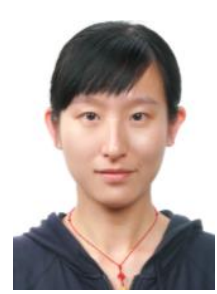

Hailing Zhao was born in Tianjin, China in 1987 Zhao has studied in Tianjin Polytechnic University, Tianjin, China, where she received her bachelor degree in economics and human resource management in 2009. She also received her master degree from economics in Pusan National University, Busan, South Korea, in 2012. Zhao is a Ph.D. candidate in economics in Pusan National University. Her major field of study is efficiency of banking, industry, and environment.

For the past, she has volunteered with the Cross-Cultural Awareness Program, which was organized by the Korean National Commission for UNESCO and supported by the ministry of education. She currently has several article published including 'Banking Performance Evaluation in China Based on Non-radial Super-efficiency Data Envelopment Analysis', 'Measurement on R\&D Efficiency of High-tech Industry in China.' 